University of Rhode Island

DigitalCommons@URI

Cancer Prevention Research Center Faculty

Publications

Cancer Prevention Research Center

2011

\title{
Baseline Stage, Severity, and Effort Effects Differentiate Stable Smokers from Maintainers and Relapsers
}

\author{
Colleen A. Redding \\ University of Rhode Island, credding@uri.edu \\ James O. Prochaska \\ University of Rhode Island, joprochaska@uri.edu \\ Andrea L. Paiva \\ University of Rhode Island, apaiva@uri.edu \\ Joseph S. Rossi \\ University of Rhode Island, jsrossi@uri.edu \\ Wayne F. Velicer \\ University of Rhode Island, VELICER@URI.EDU
}

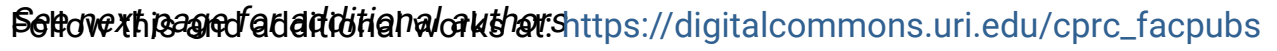

This is a pre-publication author manuscript of the final, published article.

Terms of Use

All rights reserved under copyright.

\section{Citation/Publisher Attribution}

Redding, C. A., Prochaska, J. O., Paiva, A., Rossi, J. S., Velicer, W. F., Blissmer, B. J., Greene, G. W.,...Sun, X. (2011). Baseline Stage, Severity, and Effort Effects Differentiate Stable Smokers from Maintainers and Relapsers. Substance Use \& Misuse, 46(13), 1664-1674. doi: 10.3109/10826084.2011.565853

Available at: https://doi.org/10.3109/10826084.2011.565853

This Article is brought to you for free and open access by the Cancer Prevention Research Center at DigitalCommons@URI. It has been accepted for inclusion in Cancer Prevention Research Center Faculty Publications by an authorized administrator of DigitalCommons@URI. For more information, please contact digitalcommons-group@uri.edu. 


\section{Authors}

Colleen A. Redding, James O. Prochaska, Andrea L. Paiva, Joseph S. Rossi, Wayne F. Velicer, Bryan J.

Blissmer, Geoffrey W. Greene, Mark L. Robbins, and Xiaowu Sun

This article is available at DigitalCommons@URI: https://digitalcommons.uri.edu/cprc_facpubs/28 


\title{
Baseline Stage, Severity, and Effort Effects Differentiate Stable Smokers from Maintainers and Relapsers
}

\author{
Colleen A. Redding ${ }^{1}$, James O. Prochaska ${ }^{2}$, Andrea Paiva ${ }^{1}$, Joseph S. Rossi ${ }^{2}$, Wayne \\ Velicer $^{2}$, Bryan J. Blissmer ${ }^{3}$, Geoffrey W. Greene ${ }^{4}$, Mark L. Robbins ${ }^{2}$, and Xiaowu Sun ${ }^{1}$ \\ ${ }^{1}$ Cancer Prevention Research Center, University of Rhode Island, Kingston, Rhode Island, USA \\ ${ }^{2}$ Department of Psychology, Cancer Prevention Research Center, University of Rhode Island, \\ Kingston, Rhode Island, USA \\ ${ }^{3}$ Department of Kinesiology, Cancer Prevention Research Center, University of Rhode Island, \\ Kingston, Rhode Island, USA \\ ${ }^{4}$ Department of Food Science \& Nutrition, Cancer Prevention Research Center, University of \\ Rhode Island, Kingston, Rhode Island, USA
}

\begin{abstract}
This cross-sectional study $(N=4,144)$ compared three longitudinal dynatypes (Maintainers, Relapsers, and Stable Smokers) of smokers on baseline demographics, stage, addiction severity, and transtheoretical model effort effect variables. There were significant small-to-medium-sized differences between the Stable Smokers and the other two groups on stage, severity, and effort effect variables in both treatment and control groups. There were few significant, very small differences on baseline effort variables between Maintainers and Relapsers in the control, but not the treatment group. The ability to identify Stable Smokers at baseline could permit enhanced tailored treatments that could improve population cessation rates.
\end{abstract}

\section{Keywords}

smoking cessation; maintenance; relapse; stages of change; addiction severity; transtheoretical model; processes of change; pros and cons; self-efficacy

\section{INTRODUCTION}

Most smoking cessation research has focused on the efficacy of alternative interventions with samples selected to be most ready to quit (e.g., Fiore et al., 1996, 2000; Zhu et al., 1996). As the field increasingly moves toward more population-based interventions, the full range of readiness to quit among current smokers (Velicer et al., 1995) becomes more relevant. Efficacy trials have led us to focus primarily on the transition from smoker to quitter, with relapsers often viewed as treatment failures. Considerable research has focused on predictors of successful cessation. Important predictors include addiction severity variables such as number of cigarettes smoked and time to first cigarette (e.g., Farkas et al., 1996; Velicer, Redding, Sun, \& Prochaska, 2007), demographics, such as age and education

Copyright (C) 2011 Informa Healthcare USA, Inc.

Address correspondence to Dr. Colleen A. Redding, Cancer Prevention Research Center, University of Rhode Island, 2 Chafee Road, Kingston, RI 02881; credding@uri.edu.

Declaration of Interest

The authors report no conflicts of interest. The authors alone are responsible for the content and writing of the article. 
(National Cancer Institute, 2000; Velicer et al., 2007), and stage of change variables (Prochaska, Velicer, Prochaska, \& Johnson, 2004; Velicer et al., 2007). In order to better serve the full population of smokers, better understanding of dynamic variables that could differentiate those who quit successfully (Maintainers) from those who relapse (Relapsers), and those who least likely try to quit at all (Stable Smokers) could help us improve smoking cessation interventions.

One way to increase our understanding of how change occurs is to study different patterns of change over time. This study compared three groups of smokers on the basis of their distinct patterns of change over time: those who did not quit at any of the six-month follow-ups over a 24-month period (Stable Smokers), those who did quit at one of the six-month follow-ups and at each subsequent follow-up (Maintainers), and those who did quit at one of the six month follow-ups but had relapsed by the 24-month follow-up (Relapsers). This study applied an exploratory data analysis methodology called dynamic typology that groups participants by their pattern of changes over time (Norman, Velicer, Fava, \& Prochaska, 1998; Prochaska, Velicer, DiClemente, Guadagnoli, \& Rossi, 1991). These three dynatype groups were compared on baseline variables for both treatment and control groups.

Comparing these dynatypes on baseline variables was designed to determine whether these groups could be differentiated at baseline and then to provide basic knowledge that could be used to improve cessation treatments.

These same three dynatypes (Maintainers, Relapsers, and Stable Smokers) were examined in a representative sample of smokers (Sun, Prochaska, Velicer, \& Laforge, 2007). The dynatypes were compared on their use of 14 principles and processes of change over a 24month period and clear differences were found. The Stable Smokers who were not abstinent at any of the six-month follow-ups were the most different from the other two groups. They made the poorest efforts at each assessment and almost all of the change variables showed little change in effort over time. One conclusion was that a treatment breakthrough from $25 \%$ to $30 \%$ population cessation would be more likely to emerge from more effective interventions for the Stable Smokers, the largest group, than for the Relapsers, the smallest group. To achieve a 5\% increase in overall quit rates would require preventing relapse with $78 \%$ of the Relapsers, which is not feasible. The same increase in quit rates could be achieved by helping only about $7 \%$ of the Stable Smokers to quit, which may be feasible. But first it needs to be determined whether the Stable Smokers can be differentiated from other dynatypes at baseline. In the present study, these same three dynatypes in both the treatment and control groups were compared on baseline variables representing demographic, stage, addiction severity, and transtheoretical model (TTM) effort effects.

In another longitudinal study (Velicer et al., 2007), several of these effects (demographics, stage, and addiction severity) were assessed at baseline and used to predict successful quitting at 24 months within the treatment group only. The strongest predictors of outcomes over time included both severity variables and stages of change. There were also small demographic effects (education and age) on long-term quitting. Effort effects evaluating TTM variables, such as decision-making, temptations, and processes of change, were not examined in this study. Also, none of these effects were evaluated in the control group. This study will address each of these gaps by evaluating all four effects (demographic, stage, severity, and effort) in both treatment and control groups.

The present study draws from these two recent studies to determine whether baseline variables representing demographics, stage, severity, and TTM effort effects can differentiate the three dynatypes of Maintainers, Relapsers, and Stable Smokers. In the study by Velicer et al. (2007), only two outcome groups were compared, those who were successful at 24 months and those who were not. Such grouping is the norm in outcome 
studies, but the other dynatype study (Sun et al., 2007) found that the Relapsers and Stable Smokers followed very different pathways over time, with the Stable Smokers making the poorest efforts. The question arises whether the Relapser and the Stable Smoker dynatypes, in particular, can be differentiated at baseline, which could allow interventions to improve outcomes with these groups.

\section{METHODS}

\section{Sample}

This study began with a representative sample of 4,144 smokers proactively recruited in Rhode Island by random digit dialing (RDD) procedures (Fava, Velicer, \& Prochaska, 1995). Even though this was an RDD sample, $55 \%$ were female. The mean age was about 40 years, and a little over $50 \%$ were married. The vast majority were non-Hispanic Caucasians.

Of these smokers, $42.1 \%$ were in the precontemplation stage and were not intending to quit smoking in the next six months, $40.3 \%$ were in the contemplation stage and were intending to quit in the next six months, and $17.6 \%$ were in the preparation stage and were intending to quit in the next month and had quit for at least $24 \mathrm{hr}$ in the past year (Fava et al., 1995). They smoked a mean of 20.6 cigarettes per day. About one-third of the smokers $(n=1358)$ were randomly assigned to the treatment group and about two-thirds to the assessment-only group $(n=2786)$. The treatment group was mailed tailored expert system intervention materials at baseline, three, and six months. All subjects were proactively assessed at sixmonth intervals for 24 months. Treatment outcomes and other details of this study are reported in the study by Prochaska, Velicer, Fava, Rossi, and Tsoh (2001).

Over the 24 months of the study, 3,163 (76.3\%) of the participants were Stable Smokers, $705(17 \%)$ were Maintainers, and 276 (6.6\%) were Relapsers. Table 1 presents the demographics for these three dynatypes in both the treatment and control groups. Treatment and control groups will be analyzed separately throughout so that different predictors can emerge.

\section{MEASURES}

All variables were assessed by self-report during the baseline phone survey.

\section{Demographics}

Demographic variables included Age ("What is your current age?") and Education ("How many years of school have you completed?") that involved open-ended responses. Gender, Race, and Ethnicity involved multiple-choice responses with the following categories: gender (male/female), Hispanic or Latino (yes/no), and race (Asian/black or AfricanAmerican/White/Native Hawaiian, or Other Pacific Islander/American Indian or Alaskan Native).

\section{Severity}

Severity variables reflect the degree of addiction and included the number of cigarettes smoked and time to first cigarette, two main parts of the Fagerstrom index (Heatherton, Kozlowski, Frecker, \& Fagerstrom, 1991).

\section{Stages of Change}

A three-item algorithm was used with precontemplation defined as not intending to quit smoking in the next six months, contemplation defined as intending to quit in the next six months, and preparation defined as intending to quit in the next month and having made a 
quit attempt in the past 12 months. This algorithm has been found to have strong predictive validity over 6 (DiClemente et al., 1991), 12, 18, and 24 months (Prochaska et al., 2004; Velicer et al., 2007).

\section{Decisional Balance}

The "Decisional Balance" scale assesses cognitive and motivational aspects of smoking cessation decision-making (Velicer, DiClemente, Prochaska, \& Brandenberg, 1985), with two subscales labeled the Pros and the Cons of smoking. This TTM construct also reflects effort effects (Blissmer et al., 2010). Subjects responded using a five-point Likert scale of importance ( $1=$ not at all important; $3=$ somewhat important; $5=$ very important). For this study, a six-item short form (Fava, Rossi, Velicer, \& Prochaska, 1991; Ward, Velicer, Rossi, Fava, \& Prochaska, 2004) was used. Correlations between the short form and the original length scales were .88 for both Pros and Cons.

\section{Processes of Change}

The processes are strategies that individuals (e.g., interventionists or self-changers) use to modify problem behaviors. The Processes of Change Questionnaire (Prochaska, Velicer, DiClemente, \& Fava, 1988) measures 10 processes of change in a statistically well-defined and reliable manner. Subjects responded using a five-point Likert scale of frequency of use in the past month $(1=$ never; $3=$ occasionally; $5=$ repeatedly $)$. These TTM variables reflect effort effects (Blissmer et al., 2010). Confirmatory factor analysis supported the 10-process measurement model (Prochaska, et al., 1988), with two higher order factors of five processes each labeled: experiential and behavioral. The 20-item short-form version (Fava et al., 1991) of this measure was used. Alpha coefficients were good to excellent for two-item scales and ranged from .67 to .90 with a mean of .80 . Correlations between the short-form scales and the original scales ranged from .87 to .96 .

\section{Situational Temptation}

The Situational Temptation scale (DiClemente, Prochaska, \& Gibertini, 1985: Velicer, DiClemente, Rossi, \& Prochaska, 1990) measures cue strength and parallels a measure of cessation self-efficacy. Psychometric analysis revealed a hierarchical structure with three first-order factors: Positive Social, Negative Affect, and Habit Addictive (Velicer et al., 1990). This TTM construct reflects effort effects (Blissmer et al., 2010). Subjects responded using a five-point Likert scale of temptations to smoke $(1=$ not at all tempted; $3=$ somewhat tempted; 5 = very tempted). To reduce response burden, a nine-item short form (Fava et al., 1991) was used. Correlations between the three-item short form and the original length scales were .97 for the Positive Social subscale, .98 for the Negative Affect subscale, and . 91 for the Habit Addictive subscale.

\section{Dynatype Groups}

Because all participants smoked at baseline, the three dynatypes were formed on the basis of the patterns of change in smoking from baseline to 6-, 12-, 18-, and 24-month follow-ups (Sun et al., 2007). Maintainers were defined as participants who had quit at any single assessment and all subsequent assessments or who had quit at the last assessment $(n=705$; $17 \%)$. Stable smokers were defined as those who did not quit at any of the five assessments $(n=3,163 ; 76.3 \%)$. Relapsers included participants who did quit at any assessment and later reported smoking again $(n=276 ; 6.6 \%)$. 


\section{RESULTS}

Table 1 shows the relationships between baseline demographic variables and dynatype groups in both treatment and control groups.

There were no significant differences between the three dynatypes in either the treatment or control condition for gender, race, or ethnicity. There was a significant difference in the control group for age, with the Maintainers having significantly more adults over the age of 50 years $(31.26 \%)$ than either Relapsers $(21.65 \%, h=0.219)$ or the Stable Smokers $(23.87 \%$, $h=0.166$ ). The effect size indicator Cohen's $h$ represents the standardized difference between proportions (Cohen, 1988; Rossi, 1985). Its interpretation is exactly analogous to that of Cohen's $d(h=0.20=$ small effect size; $h=0.50=$ medium effect size; $h=0.80=$ large effect size). There was a significant difference in treatment group for education, with the Stable Smoker dynatype having significantly more participants with less than a high school education $(17.12 \%)$ compared with the Maintainers $(11.42 \%, h=0.164)$ or the Relapsers $(8.54 \%, h=0.260)$.

Table 2 shows the baseline addiction and stage differences with effect sizes between dynatype groups for both control and treatment groups.

Table 2 indicates that on the two addiction variables, there were significant differences in both treatment and control groups between the Stable Smokers and the other two groups, with the Stable Smokers showing more severe addiction levels on both variables. Effect sizes for both addiction variables were in the small-to-medium range and were comparable between treatment and control groups. Both the Maintainers and the Relapsers had longer time to first cigarette than the Stable Smokers. The Stable Smokers smoked about four more cigarettes per day than both other groups. There were no significant differences between the Maintainers and Relapsers on either addiction variable in either treatment or control group.

Table 2 also shows that on the stage variable, there were significant differences in both the treatment and control groups, with the Stable Smokers having more smokers in the precontemplation stage and fewer in the preparation stage. There were no significant differences between the Maintainers and Relapsers on any of the three stages in either the control or treatment group. Comparing stage distributions in the Stable Smokers versus the other two groups combined, the effect sizes for each stage are given in Table 2. Effect sizes for precontemplation and preparation were in the small-to-medium range, while effect sizes for contemplation were quite small. Effect sizes by stage were comparable in treatment and control groups.

Table 3 shows the baseline TTM effort variable differences with effect sizes between dynatype groups for both control and treatment groups. Because most of these variables are used to tailor expert system feedback (Redding et al., 1999; Velicer \& Prochaska, 1999; Velicer et al., 1993), differences on these variables could have important implications for tailored treatments to better serve the Stable Smoker group. These variables reflect baseline effort on decision-making, affective, and behavioral skill variables that have demonstrated relationships to subsequent outcomes.

In a series of planned comparisons, significant differences in the control group were found between the Stable Smokers and the other two dynatypes on all of the TTM variables except social liberation. With 17 of the 18 TTM variables listed, the Stable Smokers were significantly worse off at baseline, with higher levels of addiction and temptations, higher pros of smoking, lower cons of smoking, and less process use. In addition, in the control group only, the Relapsers were using dramatic relief $(d=.17)$, self-liberation $(d=.15)$, and the total experiential $(d=.15)$ and behavioral $(d=.12)$ processes significantly more than the 
Maintainers. In the treatment group, these results comparing the Stable Smokers with the other two dynatypes groups were replicated on 10 of the 18 listed variables, with no significant differences observed at baseline on cons of smoking, positive social temptations, negative affect temptations, consciousness raising, dramatic relief, environmental reevaluation, social liberation, and reinforcement management.

Examining Tables 2 and 3 reveals many significant small and small-to-medium effect sizes reflecting baseline differences between the Stable Smokers and the other two dynatype groups, including addiction severity, stages of change, and effort effect variables. The effect sizes generally ranged from about 2 to .4 standard deviation $(S D)$. Effect sizes were generally comparable in both control and treatment groups.

\section{DISCUSSION}

These results show that in the control group, the Stable Smokers were consistently differentiated at baseline from the Maintainers and Relapsers by addiction severity, stage, and effort variables. A comparable pattern of results was replicated in the treatment group. In fact, the replication of these severity, stage, and effort effects across treatment and control groups is an important finding. TTM-tailored interventions were developed in part by mimicking successful patterns of change among self-changers, and so, comparable predictors of outcome groups across treatment and control groups both reflect and support this approach. Treatment and control groups are changing in the same ways. Of course, treatment and control groups change at different rates (Prochaska et al., 2001); however, the variables associated with change are comparable. Also, in the control group only, the Relapsers were using four effort variables (dramatic relief, self-liberation, total experiential process, and behavioral process sums) significantly more than the Maintainers, although these effects were fairly small. These results have important implications for enhancing interventions.

First, most smoking cessation research, by examining predictors of successful outcome, winds up grouping together Stable Smokers and Relapsers as treatment failures. In contrast, this research indicates that at baseline, the Relapsers and the Maintainers were much more similar and the Stable Smokers were the most different from the other two groups. These results indicate that Stable Smokers can be differentiated at baseline and therefore could be treated differently in interventions.

Second, the Stable Smokers differ on dynamic variables, such as addiction severity, stage, and other TTM variables, which are subject to change much more than on static variables, such as demographics, which are not subject to intentional change. Third, although the Stable Smokers were worse off at baseline on these dynamic variables, the magnitude of these differences was in the relatively small range of .2-.4 SD. With TTM-tailored interventions, a typical goal is to produce improvements in the .3-.4 SD range on these dynamic variables (Prochaska, Velicer, Guadagnoli, Rossi, \& DiClemente, 1991).

One strategy would be to identify those who are likely to remain Stable Smokers and tailor interventions to their special needs and challenges. The long-term goal would be to help this stable group take action over time. The immediate intervention goal would be to increase their effective use of the TTM effort variables by only .2-.4 SD, which should be achievable. Such improvement would help this group to have a pattern that would be more comparable to the Maintainers and the Relapsers. The assumption is that the more the Stable Smokers model early in treatment the groups who took action over time, the more likely this group would also take action over time. Some of them would relapse, but if they follow the pattern described in this study, many who took action could become Maintainers. 
Another strategy would be to apply interventions with the Stable Smokers that have been found to produce significant effects in populations of unmotivated smokers. Carpenter, Hughes, Solomon, and Callas (2004) found with a large sample of smokers in precontemplation and contemplation that $23 \%$ were abstinent at six months following five sessions of motivational interviewing delivered by telephone. This was significantly greater than $4 \%$ in the control group. They also found that in a third treatment, smoking reduction counseling utilizing nicotine replacement therapy (NRT) produced $18 \%$ abstinence at six months (Carpenter et al., 2004).

The best strategy is likely to be a combination of tailored communications that improve the use of TTM change principles and processes, and motivational and biological treatments that enhance motivation and reduce the severity of addiction simultaneously. Such combinations would counter the view of some like Farkas and colleagues (1996), Abrams, Herzog, Emmons, and Linnan (2000), and West (2005) who pit TTM variables against addiction variables rather than finding creative ways to integrate these variables theoretically and practically (Noar, Benac, \& Harris, 2007; Shiffman, 1996; Velicer et al., 2007).

This study had some limitations. Dynatypes were defined broadly (e.g., all relapsers). Examining dynatype groups in a more fine-grained manner (relapsing at one, two, or three timepoints) in future studies may provide additional useful information. The Maintainer group included those who quit at the last study timepoint, even though we could not verify that quitting was sustained later. This may have reduced differences between Maintainers and Relapsers. Follow-up timepoints were at six-month intervals. Other time intervals may prove important in the future. This sample reflects only those who were followed longitudinally and not study dropouts. Future examination of additional sample description, especially resources and functional limitations, may prove useful.

In this study, compared with the Stable Smokers, the Maintainers and Relapsers who were further along in the stages of change were using TTM effort variables and processes of change more effectively and reported less severe addiction levels. One interpretation of these results is that the Maintainers and Relapsers had less severe addiction because they were using self-change or self-control processes more to control their smoking. The traditional view has been that lighter smokers are more successful in quitting because they are less addicted (e.g., West, 2005). An alternative hypothesis is that lighter smokers are more successful because they are already utilizing change processes to control their smoking and can use these processes to further control their smoking when they take action to quit (Rossi, Prochaska, \& DiClemente, 1988). Future research needs to find ways to maximize treatment, stage, effort, and severity effects early in treatment, over the course of treatment, and long after treatment ends.

These results add to our concerns that population cessation breakthroughs are unlikely to emerge from treatment enhancements for Relapsers (Sun et al., 2007). These results indicate that in the treatment group, the Relapsers could not be differentiated from the Maintainers at baseline. Treatment could not be tailored to the special needs and challenges of Relapsers at the start of treatment, as it could for the Stable Smokers. Given their baseline advantages over the Stable Smokers, it is not surprising that the Relapsers would quit during at least one of the six-month follow-ups. But what does this group do differently over time that prevents them from sustaining their quit attempt in the way the Maintainers do?

Across 10 processes of change and over 24 months, the Relapsers on average were using five of the processes the most: dramatic relief, self-revaluation, environmental revaluation, helping relationship, and self-liberation (Sun et al., 2007). In the present study, the Relapsers in the control group were using four effort variables more than the Maintainers at baseline. 
Both the current baseline and the previous longitudinal results suggest that relapse may not be due to these smokers failing to work hard enough. They do need to adjust their strategies, however. Longitudinally, compared with Maintainers, Relapsers do not decrease their reliance on self-revaluation and decision-making and do not increase their use of counterconditioning and stimulus control (Sun et al., 2007), which would serve them better. One promising approach would be to provide expert guidance on how they can continue to parallel the Maintainers' use of change principles and processes over the long-term.

The present results and the previous longitudinal data (Sun et al., 2007; Velicer et al., 2007) support the view that there are at least two types of smokers that our current best practices fail in population cessation trials. The group in which we most often fail is the Stable Smokers who were not even trying to quit at any follow-up over a two-year period. This dynatype had the most disadvantages at baseline, including more severe addiction levels, starting in earlier stages of change, and making poorer efforts in applying change processes. This group is likely to need more intensive treatments to help them work harder to overcome their initial disadvantages. The Relapsers may also need more tailored treatments to help them to work smarter. Future research needs to determine whether treating one or both of these dynatypes differently can produce breakthroughs in population cessation rates.

\section{Acknowledgments}

This study was supported by NIH grants \#AG 024490, \#CA 50087, \#CA 27821, and \#CA 85990 to James Prochaska, \#DA 023191 to Colleen Redding, and \#CA 85999 to Wayne Velicer.

\section{GLOSSARY}

$\begin{array}{ll}\text { TTM } & \text { Transtheoretical model } \\ \text { RDD } & \text { random digit dial } \\ \text { CR } & \text { Consciousness Raising } \\ \text { DR } & \text { Dramatic Relief } \\ \text { ER } & \text { Environmental Reevaluation } \\ \text { SR } & \text { Self Reevaluation } \\ \text { SO } & \text { Social Liberation } \\ \text { HR } & \text { Helping Relationships } \\ \text { SC } & \text { Stimulus Control } \\ \text { CC } & \text { CounterConditioning } \\ \text { RM } & \text { Reinforcement Management } \\ \text { SL } & \text { Self Liberation } \\ \text { PC } & \text { Precontemplation } \\ \text { C } & \text { Contemplation } \\ \text { Prep } & \text { Preparation } \\ \text { NIH } & \text { National Institutes of Health } \\ \text { CDC } & \text { Centers for Disease Control and Prevention } \\ \text { HRSA } & \text { Health Resources and Services Administration } \\ \text { NHLBI } & \text { National Heart Lung \& Blood Institute }\end{array}$




\section{References}

Abrams DB, Herzog TA, Emmons KM, Linnan L. Stages of change versus addiction: A replication and extension. Nicotine \& Tobacco Research. 2000; 2:223-229. [PubMed: 11082822]

Blissmer B, Prochaska JO, Velicer WF, Redding CA, Rossi JS, Greene GW, et al. Common factors predicting long-term changes in multiple health behaviors. Journal of Health Psychology. 2010; 15(2):205-214. [PubMed: 20207664]

Carpenter MJ, Hughes JR, Solomon LJ, Callas PW. Both smoking reduction with nicotine replacement therapy and motivational advice increase future cessation among smokers unmotivated to quit. Journal of Consulting and Clinical Psychology. 2004; 72:371-381. [PubMed: 15279521]

Cohen, J. Statistical power analysis for the behavioral sciences. Hillsdale, NJ: Lawrence Erlbaum; 1988.

DiClemente CC, Prochaska JO, Fairhurst S, Velicer WF, Velasquez M, Rossi JS. The process of smoking cessation: An analysis of precontemplation, contemplation and preparation stages of change. Journal of Consulting and Clinical Psychology. 1991; 59:295-304. [PubMed: 2030191]

DiClemente CC, Prochaska JO, Gibertini M. Self-efficacy and the stages of self change of smoking. Cognitive Therapy and Research. 1985; 9:181-200.

Farkas AJ, Pierce JP, Zhu SH, Rosbrook B, Gilpin EA, Berry C, et al. Addiction versus stages of change models in predicting smoking cessation. Addiction. 1996; 91:1271-1280. [PubMed: 8854358]

Fava, JL.; Rossi, JS.; Velicer, WF.; Prochaska, JO. Structural confirmation of short form instruments for the transtheoretical model. Paper presented at the 99th Annual Convention of the American Psychological Association; San Francisco, CA. 1991 August.

Fava JL, Velicer WF, Prochaska JO. Applying the transtheoretical model to a representative sample of smokers. Addictive Behaviors. 1995; 20:189-203. [PubMed: 7484313]

Fiore, MC.; Bailey, WC.; Cohen, SJ.; Dorfman, SF.; Goldstein, MG.; Gritz, ER., et al. Clinical Practice Guideline No. 18 (AHCPR Publication No. 96-0692). Rockville, MD: US Department of Health and Human Services, Public Health Services, Agency for Health Care Policy and Research; 1996. Smoking cessation.

Fiore, MC.; Bailey, WC.; Cohen, SJ.; Dorfman, SF.; Goldstein, MG.; Gritz, ER., et al. Treating tobacco use and dependence: Clinical practice guideline. Rockville, MD: US Department of Health and Human Services, Public Health Service; 2000.

Heatherton TF, Kozlowski LT, Frecker RC, Fagerstrom KO. The Fagerstrom test for nicotine dependence: A revision of the Fagerstrom tolerance questionnaire. British Journal of Addiction. 1991; 86:1119-1127. [PubMed: 1932883]

National Cancer Institute. Proceedings of a conference on what works to influence cessation in the general population. National Cancer Institute Smoking and Tobacco Control Monograph No. 12. Bethesda, MD: US Department of Health and Human Services, National Institutes of Health, National Cancer Institute; 2000 November. Population based smoking cessation. NIH Publication No. 00-4892

Noar SM, Benac CN, Harris MS. Does tailoring matter? Meta-analytic review of tailored print health behavior change interventions. Psychological Bulletin. 2007; 133(4):673-693. [PubMed: 17592961]

Norman GJ, Velicer WF, Fava JL, Prochaska JO. Dynamic typology clustering within the stages of change for smoking cessation. Addictive Behaviors. 1998; 23:139-153. [PubMed: 9573419]

Prochaska JO, Velicer WF, DiClemente CC, Fava JL. Measuring processes of change: Applications to the cessation of smoking. Journal of Consulting and Clinical Psychology. 1988; 56:520-528. [PubMed: 3198809]

Prochaska JO, Velicer WF, Fava JL, Rossi JS, Tsoh JY. Evaluating a population-based recruitment approach and a stage-based expert system intervention for smoking cessation. Addictive Behaviors. 2001; 26:583-602. [PubMed: 11456079] 
Prochaska JO, Velicer WF, Guadagnoli E, Rossi JS, DiClemente CC. Patterns of change: Dynamic typology applied to smoking cessation. Multivariate Behavioral Research. 1991; 26:83-107.

Prochaska JO, Velicer WF, Prochaska JM, Johnson J. Size, consistency and stability of stage effects for smoking cessation. Addictive Behaviors. 2004; 29:207-217. [PubMed: 14667431]

Redding CA, Prochaska JO, Pallonen UE, Rossi JS, Velicer WF, Rossi SR, et al. Transtheoretical individualized multimedia expert systems targeting adolescents' health behaviors. Cognitive \& Behavioral Practice. 1999; 6(2):144-153.

Rossi JS. Tables of effect size for $z$ score tests of differences between proportions and between correlation coefficients. Educational and Psychological Measurement. 1985; 45:737-743.

Rossi JS, Prochaska JO, DiClemente CC. Processes of change in heavy and light smokers. Journal of Substance Abuse. 1988; 1:1-9. [PubMed: 2485274]

Shiffman S. "Addiction versus stages of change models" vs. "addiction and stages of change models". Addiction. 1996; 91(9):1289-1290. [PubMed: 8854364]

Sun X, Prochaska JO, Velicer WF, Laforge RG. Transtheoretical principles and processes for quitting smoking: A 24-month comparison of a representative sample of quitters, relapsers, and nonquitters. Addictive Behaviors. 2007; 32:2707-2726. [PubMed: 17499935]

Velicer WF, DiClemente CC, Prochaska JO, Brandenberg N. A decisional balance measure for assessing and predicting smoking status. Journal of Personality and Social Psychology. 1985; 48:1279-1289. [PubMed: 3998990]

Velicer WF, DiClemente CC, Rossi JS, Prochaska JO. Relapse situations and self-efficacy: An integrative model. Addictive Behaviors. 1990; 15:271-283. [PubMed: 2378287]

Velicer WF, Fava JL, Prochaska JO, Abrams DB, Emmons KM, Pierce JP. Distribution of smokers by stage in three representative samples. Preventive Medicine. 1995; 24:401-411. [PubMed: 7479632]

Velicer WF, Prochaska JO. An expert system intervention for smoking cessation. Patient Education and Counseling. 1999; 36:119-129. [PubMed: 10223017]

Velicer WF, Prochaska JO, Bellis JM, DiClemente CC, Rossi JS, Fava JL, et al. An expert system intervention for smoking cessation. Addictive Behaviors. 1993; 18:269-290. [PubMed: 8342440]

Velicer WF, Redding CA, Sun X, Prochaska JO. Demographic variables, smoking variables, and outcome across five studies. Health Psychology. 2007; 26(3):278-287. [PubMed: 17500614]

Ward RM, Velicer WF, Rossi JS, Fava JL, Prochaska JO. Factorial invariance and internal consistency for the decisional balance inventory—Short form. Addictive Behaviors. 2004; 29:953-958. [PubMed: 15219341]

West R. Time for a change: Putting the transtheoretical (stages of change) model to rest [Editorial]. Addiction. 2005; 100(8):1036-1039. [PubMed: 16042624]

Zhu S, Stretch V, Balabanis M, Rosbrook B, Sadler G, Pierce J. Telephone counseling for smoking cessation: Effects of single-session and multiple-session interventions. Journal of Consulting and Clinical Psychology. 1996; 64:202-211. [PubMed: 8907100]

\section{Biographies}

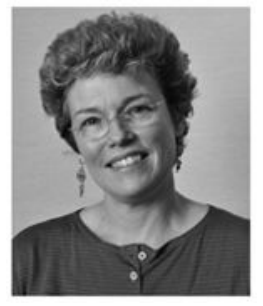

Colleen A. Redding, Ph.D., is a Research Professor at the Cancer Prevention Research Center and an Adjunct Professor of Psychology at the University of Rhode Island (URI). She has published more than 70 papers and chapters on diverse topics in Health Psychology and Behavioral Medicine. Her contributions include pioneering the development and 
application of tailored computer-delivered interventions for health behavior change, especially in high-risk populations. She is one of the principal researchers using the TTM of behavior change in new research areas such as sexual health promotion, multiple health risk behaviors, sun protection, healthy diet, sustainability, and stress management. In addition to the TTM and mechanisms of behavior change, she is also interested in familial and multilevel influences on health risk behaviors. She is an editor and reviewer for many behavioral science journals. She has been an investigator on at least $25 \mathrm{NIH}$ and CDC research grants.

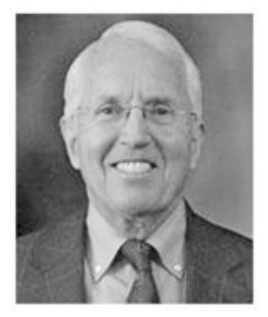

James O. Prochaska, Ph.D., is the Director of Cancer Prevention Research Center and a Professor of Clinical and Health Psychology at the URI. He is the author of over 350 publications, including three books, namely, Changing for Good, Systems of Psychotherapy, and The Transtheoretical Approach. He is internationally recognized for his work as a developer of the stage model of behavior change. He is the principal investigator on over $\$ 70$ million dollars in research grants for the prevention of cancer and other chronic diseases. He is the founder of Pro-Change Behavior Systems. Dr. Prochaska has won numerous awards, including the Top Five Most Cited Authors in Psychology from the American Psychology Society and an Innovator's Award from the Robert Wood Johnson Foundation, and is the first psychologist to win a Medal of Honor for Clinical Research from the American Cancer Society.

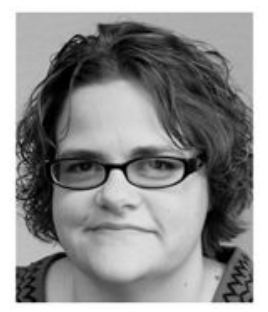

Andrea Paiva, Ph.D., received her bachelor's degree in Psychology and Health Policy Management from the Providence College and her MA and Ph.D. degrees in Experimental Psychology/Behavioral Science from the URI. Dr. Paiva is an Assistant Research Professor at the Cancer Prevention Research Center and an Adjunct Professor of Psychology at the URI. Her primary interest is the application of the TTM for health behavior change. She has worked with a variety of health behaviors, including smoking cessation, adolescent drug and alcohol use, college drinking, diet, exercise, and decision-making for health care, organ donation, and blood donation. In addition to the mechanisms of behavior change, her research interests include methodology and statistics and use of technology in behavior change interventions. 


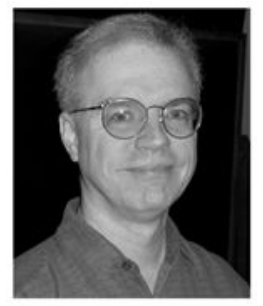

Joseph S. Rossi, Ph.D., is a Professor and the Director of the Behavioral Science Ph.D. program in the Department of Psychology, and the Director of Research at the Cancer Prevention Research Center at the URI. He has been the principal investigator or coinvestigator on more than 50 grants and has published more than 150 papers and chapters. In 1996, the American Psychological Society and the Institute for Scientific Information listed Dr. Rossi 5th in author impact (citations/paper) and 12th in number of citations (APS Observer, January 1996, pp. 14-18). In 2006, he was named one of the most highly cited researchers in the world in the fields of psychology/psychiatry by Thomson Reuters (http://isihighlycited.com/). He won the URI's Scholarly Excellence Award in 2003, was elected to membership in the Society of Multivariate Experimental Psychology in 1995, and is a fellow of Division 5 of the American Psychological Association. Dr. Rossi is one of the principal developers of the TTM of health behavior change. His areas of interest include quantitative psychology, health promotion and disease prevention, and expert system development for health behavior change. Dr. Rossi is a member of the URI's Institutional Review Board.

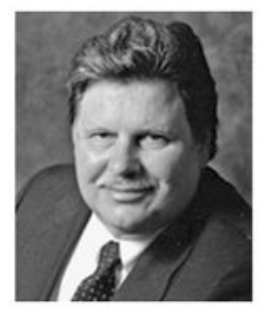

Wayne Velicer, Ph.D., is the Co-Director of the Cancer Prevention Research Center and a Professor of Psychology at the URI. He has published more than 250 papers on topics in health psychology and behavioral statistics. In health psychology, his contributions include pioneering the application of computer-based interventions to health promotion. He is one of the principal developers of the TTM of behavior change. In behavioral statistics, his contributions include refining factor analysis and component analysis, pioneering the application of time series analysis to the behavioral sciences, and improving methods for measurement development. He was identified as one of the highest impact authors in psychology (average citation per paper) by the major studies in 1992, 1996, and 2003. He has been the Principal Investigator or co-PI on more than $\$ 100$ million in research grants. He has been a Visiting Professor at the University of Western Ontario (London, Canada), Macquarie University (Sydney, Australia), the University of Maastricht (Maastricht, the Netherlands), the University of New South Wales (Sydney, Australia), the University of Marburg (Marburg, Germany), and the Queensland University of Technology (Brisbane, Australia). 


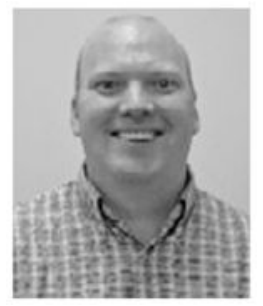

Bryan J. Blissmer, Ph.D., is an Associate Professor in the Department of Kinesiology and an Associate Research Professor at the Cancer Prevention Research Center at the URI. Dr. Blissmer's research focuses on delivering interventions to promote a healthy lifestyle as well as analysis of psychosocial outcomes of those interventions. He collaborates with faculty in Psychology and Nutrition and his research has included populations ranging from adolescents to older adults. His funding from the American Cancer Society examined the best ways to get individuals with multiple risk factors (smoking, sedentary, poor diet) to change their behaviors to promote health and reduce their risk of developing cancer. $\mathrm{He}$ teaches both graduate and undergraduate courses in the Department of Kinesiology.

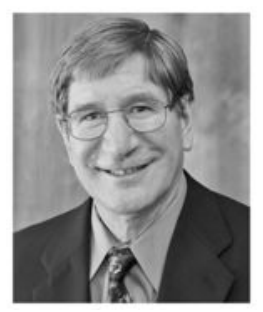

Geoffrey W. Greene, Ph.D., received his bachelor's degree in Anthropology from Columbia College, Columbia University, his MS degree in Nutrition and Public Health from Teachers College, Columbia University, an MPH in International Health from University of Hawaii at Manoa, and his Ph.D. in Nutrition from the Pennsylvania State University. His professional employment includes WIC Program Coordinator, Department of Health, State of Hawaii; Nutritionist, Waikiki Health Center; Nutrition Coordinator, College of Medicine and Dentistry of New Jersey—New Jersey School of Osteopathic Medicine; and Assistant Professor, Pennsylvania State University. He is currently a Professor and the Director of Dietetic Internship, URI. Dr. Greene's research focuses on behavior change for chronic disease risk reduction and obesity prevention.

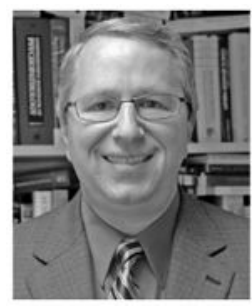

Mark L. Robbins, Ph.D., is a Clinical Health Psychologist and an Associate Professor in the Psychology Department at the URI. He has developed a program of research applying the TTM to decision-making in deceased and living organ donation and transplantation, blood donation, and advanced care planning. He has been the Principal Investigator on three HRSA-funded randomized clinical trials to increase family consent for organ donation and to increase organ donation intent. He is currently funded by NHLBI to develop a TTMbased intervention to increase blood donation among African-Americans in the context of 
sickle cell disease. His research has had an emphasis on addressing health disparities and on cultural tailoring for health decision-making. Dr. Robbins teaches undergraduate courses and mentors graduate students in URI's APA-approved Clinical Psychology graduate program.

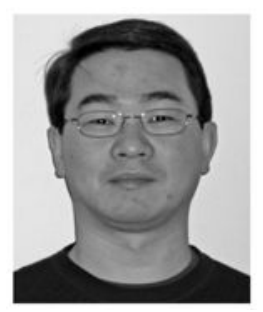

Xiaowu Sun, Ph.D., Senior Principal Scientist at CareFusion Clinical Research, has 20 years of experience in biostatistics. He was a postdoctoral fellow at Cancer Prevention Research Center at the URI, and has served as a biostatistician for multiple NIH projects. Dr. Sun conducts methodological and applied research on risk-adjustment models and hospital-acquired infections. His research interests include observational data analysis, public reporting, and outcomes research. He has coauthored over 20 publications. 


\section{TABLE 1}

Baseline demographic differences between dynatypes for control and treatment groups

\begin{tabular}{|c|c|c|c|c|}
\hline & Maintainer $(N=705)$ & Relapser $(N=276)$ & Stable Smoker $(N=\mathbf{3 , 1 6 3})$ & \\
\hline Variable & $\%$ & $\%$ & $\%$ & $\chi^{2}$ \\
\hline \multicolumn{5}{|l|}{ Age } \\
\hline Control group & & & & $12.08^{* *}$ \\
\hline Less than 50 years & 68.74 & 78.35 & 76.13 & \\
\hline $50+$ years & 31.26 & 21.65 & 23.87 & \\
\hline Treatment group & & & & 0.26 \\
\hline Less than 50 years & 74.02 & 76.83 & 74.56 & \\
\hline $50+$ years & 25.98 & 23.17 & 25.44 & \\
\hline \multicolumn{5}{|l|}{ Gender } \\
\hline Control group & & & & 4.04 \\
\hline Male & 39.69 & 45.88 & 44.65 & \\
\hline Female & 60.31 & 54.12 & 55.35 & \\
\hline Treatment group & & & & 0.50 \\
\hline Male & 44.49 & 48.78 & 44.91 & \\
\hline Female & 55.51 & 51.22 & 55.09 & \\
\hline \multicolumn{5}{|l|}{ Education } \\
\hline Control group & & & & 9.33 \\
\hline$<12$ & 18.18 & 14.43 & 20.74 & \\
\hline 12 & 39.02 & 41.24 & 41.01 & \\
\hline $13-15$ & 26.61 & 30.41 & 25.08 & \\
\hline $16+$ & 16.19 & 13.92 & 13.17 & \\
\hline Treatment group & & & & $13.52^{*}$ \\
\hline$<12$ & 11.42 & 8.54 & 17.12 & \\
\hline 12 & 39.76 & 43.90 & 41.68 & \\
\hline $13-15$ & 26.77 & 26.83 & 25.83 & \\
\hline $16+$ & 22.05 & 20.73 & 15.36 & \\
\hline \multicolumn{5}{|l|}{ Hispanic } \\
\hline Control group & & & & 0.47 \\
\hline No & 98.23 & 97.92 & 97.71 & \\
\hline Yes & 1.77 & 2.08 & 2.29 & \\
\hline Treatment group & & & & 0.24 \\
\hline No & 98.02 & 98.78 & 98.33 & \\
\hline Yes & 1.98 & 1.22 & 1.67 & \\
\hline \multicolumn{5}{|l|}{ Race } \\
\hline Control group & & & & 4.28 \\
\hline White & 96.45 & 95.34 & 94.67 & \\
\hline Black & 2.22 & 3.63 & 3.27 & \\
\hline Asian/Pacific & 0.44 & 0.00 & 0.37 & \\
\hline American Indian/Alaskan & 0.89 & 1.04 & 1.68 & \\
\hline
\end{tabular}




\begin{tabular}{|c|c|c|c|c|}
\hline & Maintainer $(N=705)$ & Relapser $(N=276)$ & Stable Smoker $(N=3,163)$ & \\
\hline Variable & $\%$ & $\%$ & $\%$ & $\chi^{2}$ \\
\hline Treatment group & & & & 2.49 \\
\hline White & 97.23 & 97.56 & 96.86 & \\
\hline Black & 1.19 & 0.00 & 1.47 & \\
\hline Asian/Pacific & 0.40 & 1.22 & 0.39 & \\
\hline American Indian/Alaskan & 1.19 & 1.22 & 1.28 & \\
\hline
\end{tabular}




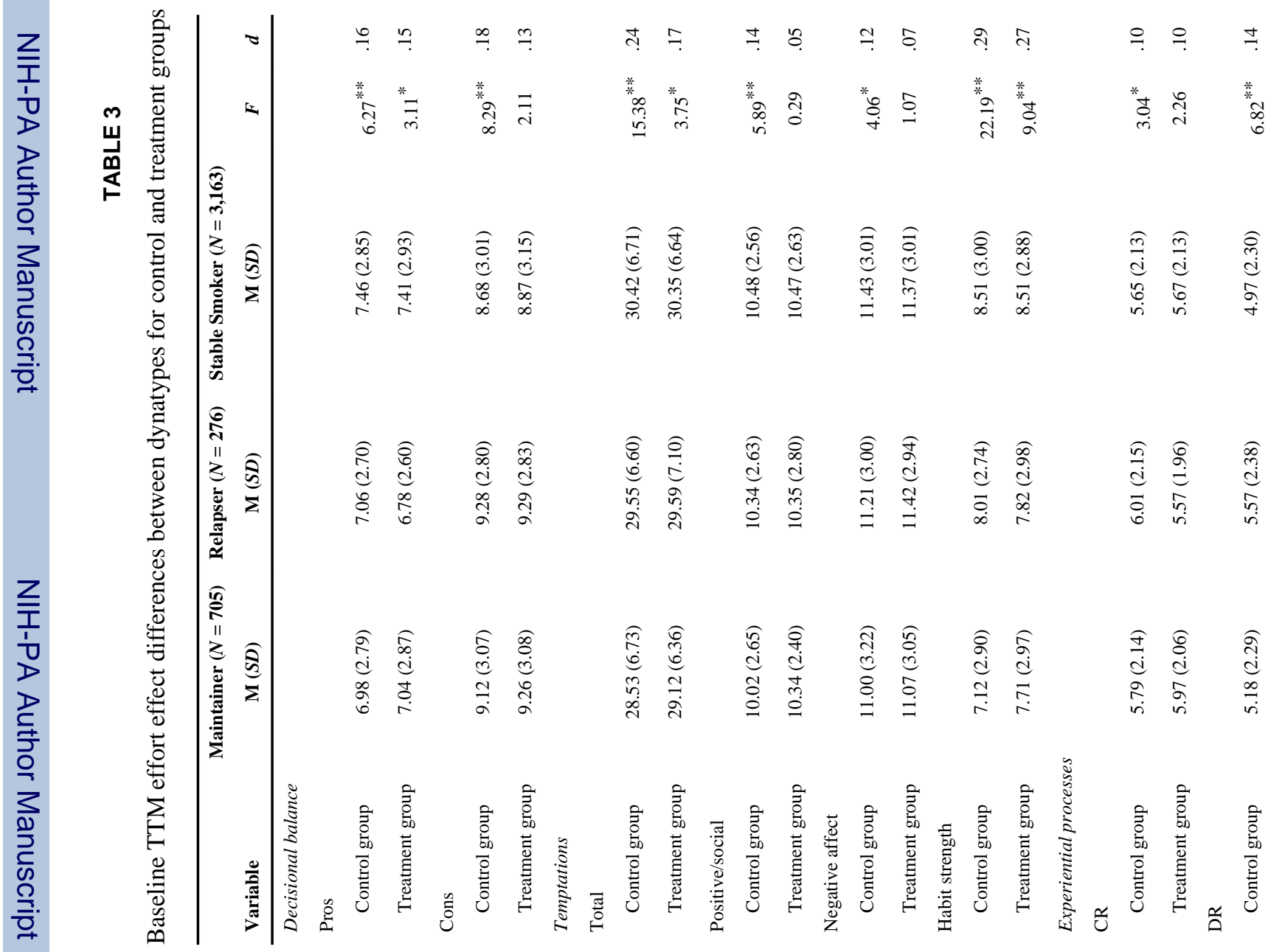


Redding et al.

Page 19

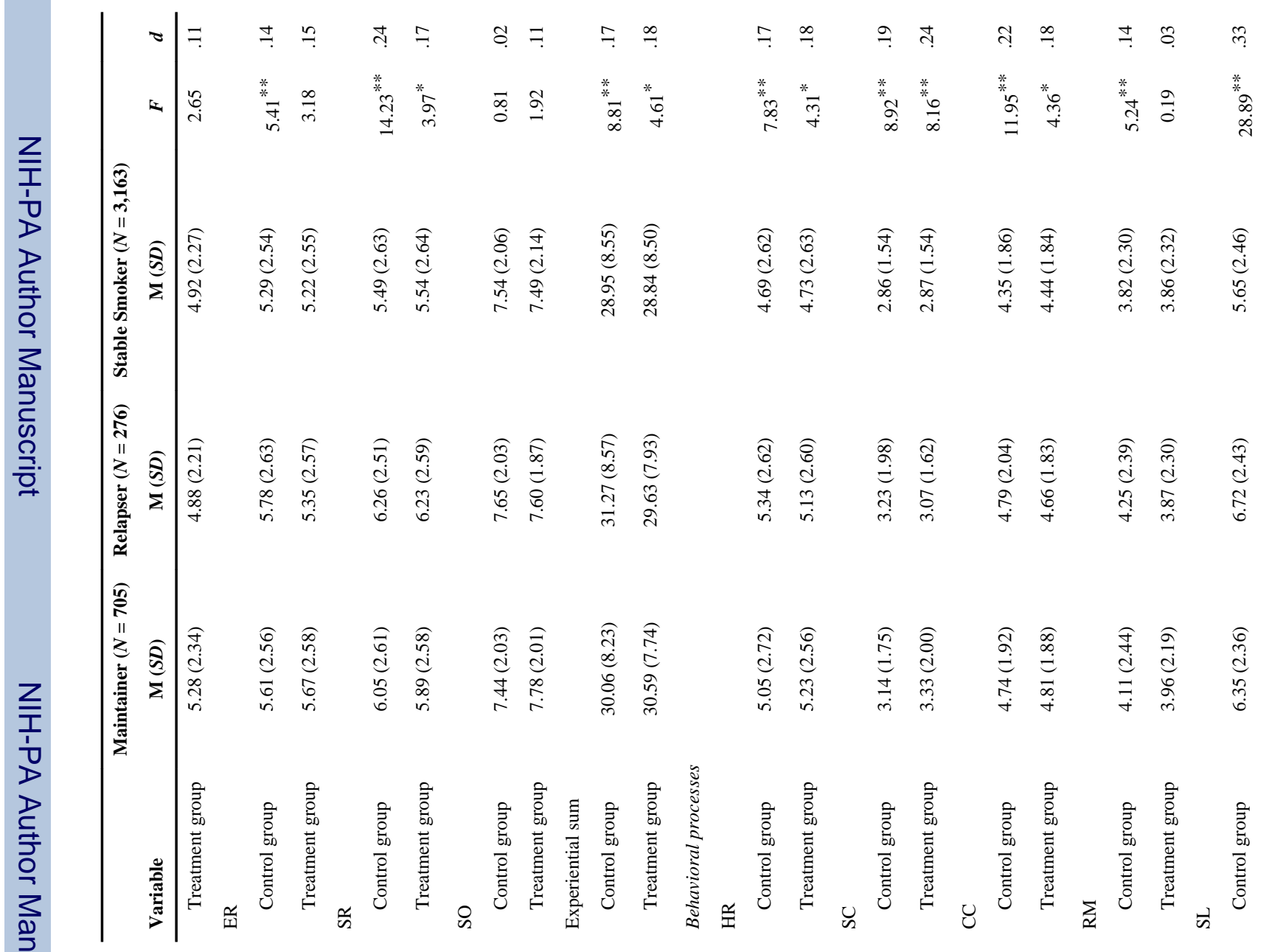




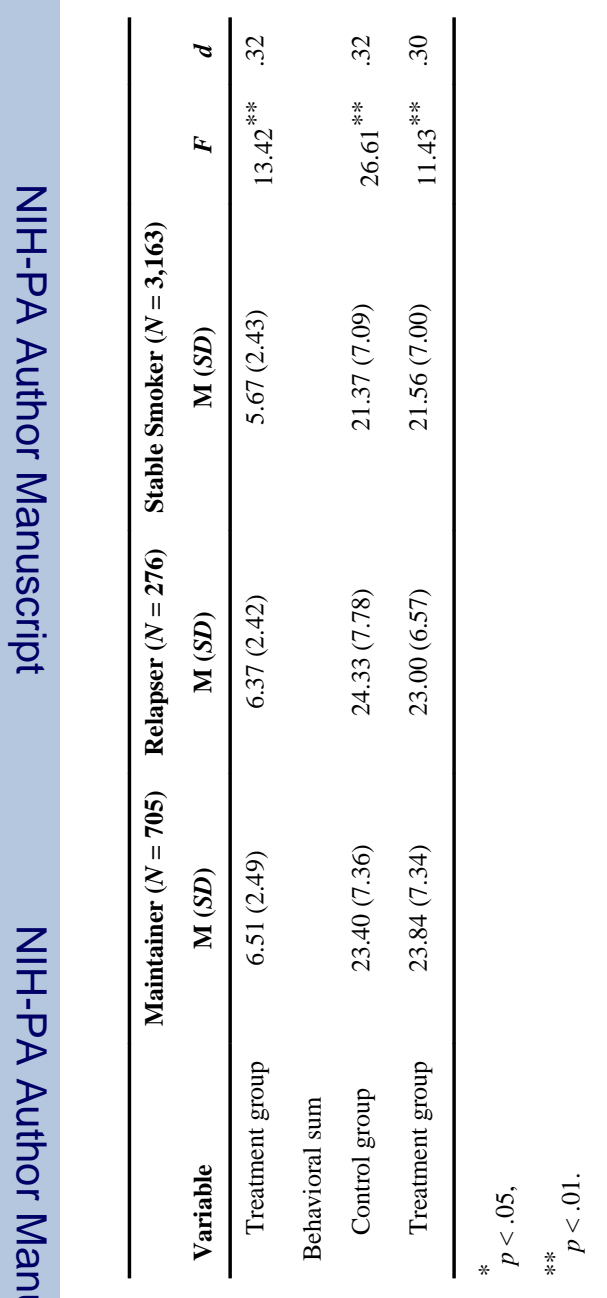

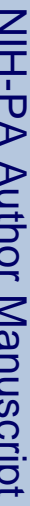

